\title{
Comparison of Mobile LIDAR Technique with Terrestrial Methods in Digital Map Production
}

\author{
Gokhan Kara \\ Ilbank AS Department of Spatial Planning \\ Ziraat Mah. 657. Sok No:14 Altındağ, Ankara, Turkey \\ E mail: gokhank@ilbank.gov.tr \\ Huseyin Kemaldere (Corresponding author) \\ Zonguldak Bulent Ecevit University \\ Department of Geomatics Engineering \\ Zonguldak, Turkey \\ E mail: kemaldere@hotmail.com
}

\begin{abstract}
Terrestrial methods and photogrammetric method are generally used in the production of maps. In recent years, along with these two methods, the Mobile LIDAR (Light Detection and Ranging) technique has begun to be employed in the production of maps. The Mobile LIDAR technique has some advantages and disadvantages. The most important advantages of the system is it's speed and it's capability of scanning millions of points called point cloud in a very short time. Topographic structure and superstructure of the project area should be suitable for Mobile LIDAR technique. Besides, the cost of the system is very high and data storage problem can not be ignored. These can be listed as the disadvantages of the system. In this study, the maps of the same region produced by terrestrial methods and Mobile LIDAR technique are compared in terms of spatial accuracy and the accuracy of the Mobile LIDAR technique was examined. Approximately 30,000 detail points were measured by both methods and horizontal coordinates and orthometric heights were calculated. The differences in the positions of these 30.000 detail points obtained from both methods were lower than the limit values specified in the Large Scale Map and Map Information Production Regulation of Turkey. This means that the accuracy of the detail point locations measured by Mobile LIDAR is acceptable.
\end{abstract}

Keywords: Mobile LIDAR, Digital map production, GNSS, Terrestrial methods

DOI: $10.7176 / \mathrm{JSTR} / 5-3-21$

\section{Sayısal Hâlihazır Harita Üretiminde Mobil LIDAR Tekniği ile Yersel Yöntemlerin Karşılaştırılması}

\section{Özet}

Sayısal hâlihazır harita üretiminde genellikle klasik yersel yöntemler ve fotogrametrik yöntem kullanılmaktadır. Son yıllarda bu iki yöntemin yanı sıra Mobil LIDAR tekniği de sayısal hâlihazır harita üretiminde kendisine yer bulmaya başlamıştır. Haritalanacak alanı çok hızlı bir şekilde tarayarak alım yapabilmesi ve milyonlarca noktadan oluşan nokta bulutu üreterek arazideki detay noktalarının neredeyse tamamını ölçebilmesi tekniğin en önemli avantajıdır. Haritası üretilecek bölgenin topografik yapısının ve üst yapısının Mobil LIDAR tekniği için uygun olması gerekliliği, sistemin maliyetinin çok yüksek olması ve veri depolama problemleri tekniğin dezavantajları olarak sıralanabilir. Bu çalışmada, aynı bölgenin hem yersel yöntemle hem de Mobil LIDAR tekniği ile üretilmiş sayısal hâlihazır haritaları konumsal doğruluk bakımından karşılaştırılmış ve Mobil LIDAR tekniğinin doğruluğu irdelenmiştir. Haritası üretilen bölgede yaklaşık olarak 30.000 adet detay noktası her iki yöntemle de ölçülmüş ve yatay koordinatları ile ortometrik yükseklikleri hesaplanmıştır. Bu 30.000 adet detay noktasının her iki yöntemden elde edilen konumlarının farkları Büyük Ölçekli Harita ve Harita Bilgileri Üretim Yönetmeliği’nde (BÖHHBÜY) belirtilen sınır değerlerden düşük çıkmıştır. Bu da, Mobil LIDAR'la ölçülen detay noktası konumlarının doğruluğunun kabul edilebilir düzeyde olduğu anlamına gelmektedir.

Anahtar Kelimeler: Mobil LIDAR, Sayısal harita üretimi, GNSS, Yersel yöntemler

192 | P a g e

www.iiste.org 


\section{1) Giriş}

Günümüz mühendislik projelerinin birçoğunda, altlık olarak kullanmak üzere hâlihazır haritalara ihtiyaç duyulmaktadır. Hâlihazır harita üretiminde, klasik yersel yöntemler ve fotogrametrik yöntemin yanı sıra, gelişen teknolojinin bir ürünü olan LIDAR da son yıllarda kullanılmaya başlanmıştır.

LIDAR sistemi, uçak, araba, gemi gibi çeşitli araçlara takılarak veya zemine sabitlenerek kullanılabilmektedir. Temelinde lazer tarama teknolojisi olan LIDAR sistemi, GNSS (Global Navigation Satellite Systems) ve IMU (Inertial Measurement Unit) teknolojileriyle de bütünleştirilerek oluşturulmuş bir veri toplama yöntemidir. Tarama işlemini lazer sensörler, anlık konum belirleme işlemini GNSS, anlık yön ve dönüklük belirleme işlemini de IMU yapmaktadir.

Bu çalışmada, Mobil (arabaya takılı) LIDAR sistemi ile üretilen sayısal halihazır haritaların, BÖHHBÜY'e göre üretilen halihazır harita standartlarına uygunluğu incelenmiștir. Bu kapsamda, Türkiye'nin Ordu İli Akkuş İlçesi'nde yersel yöntemlerle üretilen sayısal halihazır harita ile Koyuncu LIDAR Harita ve Mühendislik Firması tarafından Mobil LIDAR tekniği ile üretilen sayısal halihazır harita konumsal doğruluk bakımından karşılaştırılarak doğruluk analizi yapılmıştır.

\section{2) Yersel Yöntemlerle Sayısal Halihazır Harita Üretimi}

Harita Genel Müdürlüğü’ne göre harita; “İnsanoğlunun yaşadı̆̆ veya ilgilendiği alanın tamamında veya bir kısmında yer alan fiziksel detayların, bu detaylarla ilgili bilgilerin veya bu alanda meydana gelen olgularla ilgili bilgilerin, genellikle düz bir yüzey üzerinde, belli bir ölçekte gösterimidir" (HGM, 2019).

Halihazır harita, belirlenen bir proje sınırı içinde halihazırda bulunan durumu gösteren haritalardır. BÖHHBÜY esaslarına göre üretilen halihazır haritalarda, çalışılan sahada yer alan ölçüm noktaları (nirengi, poligon, nivelman noktaları), doğal ve yapay objeler (ağaçlar, akarsular, binalar, yollar, kaldırımlar, direkler, duvarlar, rögarlar, trafolar vb.), cadde ve sokak isimleri, kat adetleri, sınırlar, eş yükseklik eğrileri gibi tüm detaylar yer alır.

Yersel yöntemlerle sayısal halihazır harita üretim teknikleri, teknolojik gelişmelere paralel olarak gelişen ölçme aletlerinin kullanımına bağlı olarak evrim geçirmiştir. Basit bir ölçme aleti olan prizmaların kullanıldığı prizmatik yöntem zaman içerisinde yerini ilk olarak mekanik, sonrasında elektronik takeometrelerle gerçekleştirilen takeometrik yönteme bırakmış, devamında da GNSS tekniği takeometrik yöntemin yerini almıştır.

\section{1) Küresel Navigasyon Uydu Sistemleri (GNSS)}

GNSS, herhangi bir zamanda, dünyanın herhangi bir yerinde bulunan bir kullanıcının konumunu, hassas zaman bilgisi ve uzay geriden kestirme tekniğine dayalı olarak belirleyen bir uydu ölçme sistemidir. Dünya genelinde aktif olarak kullanılan sistemler;

- NAVSTAR GPS (ABD),

- GLONASS (Rusya),

- BEIDOU (Compass-Çin Uydu Tabanlı Küresel Konumlama Sistemi)

- Galileo Konum Belirleme Sistemi (Avrupa Birliği)

- QZSS: Japon Uydu Tabanlı Konumlama Sistemi’dir.

GNSS ile kod pseudorange (kod ön uzunluğu) ve taşıyıcı dalga fazı olmak üzere iki temel büyüklük gözlenmektedir. Jeodezik ölçmeler gibi yüksek duyarlılık gerektiren çalışmalarda, kod gözlemlerine göre çok daha hassas sonuçlar veren taşıyıcı dalga faz gözlemleri kullanılır. Kod ölçüleri ise navigasyon amaçlı anlık uygulamalar gibi çok büyük hassasiyet gerektirmeyen çalışmalar için uygundur (Sickle, 1996).

\subsubsection{GNSS ile Konum Belirleme Yöntemleri}

GNSS'de mutlak ve göreli olmak üzere iki tür konum belirleme yöntemi bulunmaktadır. Mutlak konum belirlemede tek bir GNSS alıcısıyla, en az dört uydudan kod gözlemleri yapılarak alıcının bulunduğu noktanın koordinatları belirlenmektedir. Göreli konum belirlemede ise noktaların koordinatları, koordinatı bilinen noktalara göre hesaplanmaktadır (Eren \& Uzel, 1995; Kahveci \& Yıldız, 2001). 


\subsubsection{Göreli Konum Belirleme Yöntemleri}

İki nokta arasındaki baz vektörünün belirlenmesi olarak da tanımlanabilen göreli konum belirleme yönteminde, konumu belirlenecek noktalardaki alıcıların, referans noktalarında ölçüm yapan alıcılarla aynı uydulara eş zamanlı gözlem yapması gerekmektedir. Nokta koordinatları, yapılan ölçümlerin GNSS yazılımlarında değerlendirilmesi sonucu elde edilmektedir. Göreli konum belirleme yöntemleri statik ölçme yöntemi, hızlı statik ölçme yöntemi, tekrarlı ölçme yöntemi, dur-git ölçme yöntemi ve kinematik ölçme yöntemi olmak üzere beş gruba ayrılmaktadır (Hofmann, Lichtenegger \& Collins, 1997; Teunissen \& Kleusberg, 1998).

\subsubsection{Diğer Konum Belirleme Yöntemleri}

Temelde göreli konum belirleme yöntemleriyle aynı mantıkta uygulanan diğer konum belirleme yöntemleri Diferansiyel GNSS (DGNSS) ve Gerçek Zamanlı Kinematik GNSS (GZK GNSS) dir. GZK GNSS ile arazideki bir noktanın yatay koordinatları $\pm 2-3 \mathrm{~cm}$ ile belirlemekte ve yine bir noktanın araziye aplikasyonu da $\pm 2-3 \mathrm{~cm}$ 'lik bir hassasiyetle yapılabilmektedir (Arslanoğlu, 2002).

\section{2) Detay Noktalarının Ölçülmesi (Detay Alımı)}

Bir arazi parçasının haritasının yapılabilmesi için, o arazi parçasında yer alan bütün doğal ve yapay objelerin (detay noktalarının) yatay ve düş̧ey konumlarının hesaplanması gerekmektedir. Detay noktalarının konumlarının hesaplanabilmesi için yapılan ölçüm işlemine detay alımı denir. Detay alımı yapılırken kullanılan ölçü aletleri ve ölçü yöntemi, arazinin büyüklüğüne ve istenilen hassasiyete bağlıdır. Detay alımı için ölçü aleti olarak genellikle GNSS alıcıları ve Total Station cihazları kullanılır.

Haritalar üretilirken kullanılması gereken yükseklikler, karaların altında da devam ettiği varsayılan denizlerin ortalama seviyesi olarak tanımlanan geoidden itibaren olan ortometrik yüksekliklerdir. GNSS tekniği ile detay noktalarının referans elipsoidine olan düşey uzaklıkları, diğer bir ifadeyle elipsoidal yükseklikleri elde edilir. Bu nedenle, harita üretiminde detay noktalarının yükseklikleri GNSS ile direkt olarak belirlenemez. Bu iş için, ya ortometrik yükseklik farkı ölçme yöntemlerinden olan geometrik ya da trigonometrik nivelman yöntemleri kullanılmalı ya da GNSS nivelmanı uygulanmalıdır.

\section{3) LIDAR ile Halihazır Harita Üretimi}

LIDAR, konumsal veri toplama yöntemi olup 1990'lardan beri sık kullanılmaya başlanmıştır. Lazer tarayıcı; havada, yerde, uzayda ve mobil olarak değişik platformlarda kullanılabilir. Yer yüzeyi veya objelerin, amaca göre oluşturulan bir ölçme planıyla taranarak 3 boyutlu (3B) modeli oluşturulabilir. LIDAR ile yeryüzünün Sayısal Arazi Modeli (SAM), Sayısal Yüzey Modeli (SYM), yükseklik modeli ve topografik modeli gibi modelleri, yüksek doğrulukta ve hızlı bir şekilde oluşturulabilir. Bu sistem ile üretilen modeller, çalışmanın amacına göre değişebilecek şekilde milyonlarla hatta milyarlarla ifade edilebilen nokta bulutunu içerir. Bu nokta bulutunun her bir noktasında 3B koordinat verisi bulunmaktadır ve nokta bulutu yoğunluğu ilgili yüzeye göre değişebilmektedir.

Çalışma prensibi radara benzeyen LIDAR, mikrodalga yerine lazer ışını kullanmaktadır. Durulan nokta ile hedef nokta arasındaki mesafe, lazerin kaynağından çıkıp hedeften yansıyarak tekrar kaynağına dönünceye kadar geçen sürenin ışık hızıyla çarpılmasıyla elde edilir. Burada lazerin, kaynaktan hedefe ve hedeften kaynağa tekrarlı yolculuğu söz konusu olduğu için durulan nokta ile hedef nokta arasındaki mesafe, hesaplanan mesafenin yarısı kadardır. Görüntü işleme uygulamalarında problem yaratan, olumsuz hava koşullarında çekilmiş görüntülerin işlenmesinde, yüksek çözünürlüğe sahip olan LIDAR yeterli doğruluğu sağlamaktadır (Yalçın, 2014).

\section{1) LIDAR Çeşitleri}

Lazer tarayıcılar, yersel ve hava LIDAR'ı olmak üzere iki farklı şekilde kullanılabilmektedir. Yersel LIDAR'ın, hava aracına takılı hava LIDAR'ından farkı, tarama yapılırken hareket etmemesidir. Sadece Mobil LIDAR'in tarama şekli hava aracına takılı lazer tarayıcılarla aynıdır.

\subsection{1) Mobil LIDAR}

Karada ya da deniz, göl, akarsu gibi bir su yüzeyinde hareket eden herhangi bir araca monte edilebilen ya da sirtta taşınabilen bir aparat ile kullanılabilen Mobil LIDAR ile çok geniş alanların haritalanması kısa süre içinde

194 | P a g e

www.iiste.org 
yapılabilmektedir. Milyonlarca noktadan oluşan nokta bulutu sayesinde, klasik yöntemlerle yapılan ölçümlerde atlanılan ya da fark edilemeyen detaylar Mobil LIDAR ile yakalanabilmektedir (Koç, Taşdemir \& Dinç, 2015).

Mobil LIDAR'lar; hassas konum bilgisi sağlayan bir adet GNSS alıcısı, $360^{\circ}$ panoramik fotoğraf çekebilen bir adet kamera, sarsıntı hatalarını engelleyen bir adet IMU ve bir adet lazer tarayıcıdan ibarettir (Şekil 1) (Tepeköylü, 2016).

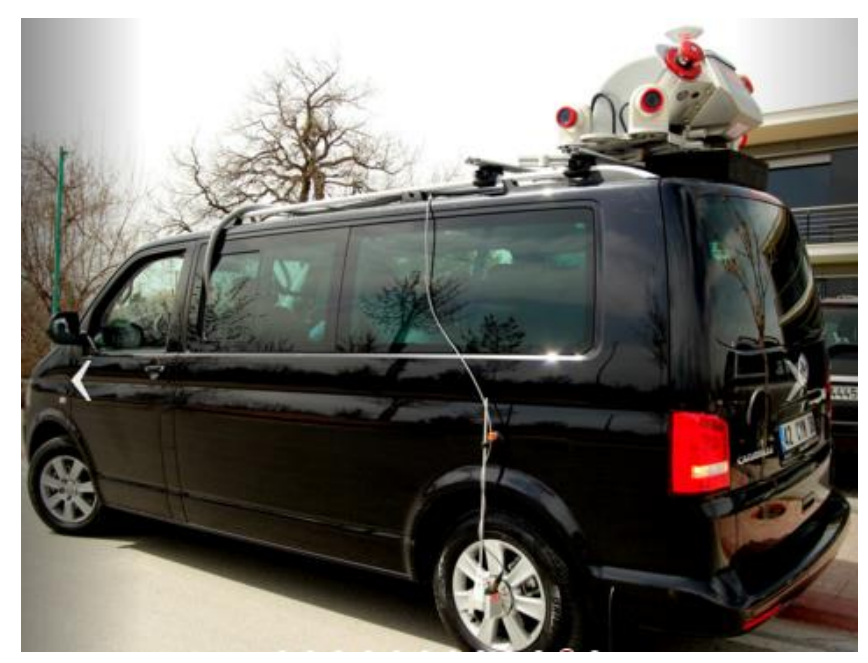

Şekil 1. Mobil LIDAR sistemi örneği (KLHM, 2019)

\section{4) Yersel Yöntem ve Mobil LIDAR Tekniği ile Üretilen Sayısal Halihazır Haritaların Karşılaştırılması}

Bu bölümde; aynı bölgenin hem yersel yöntemle hem de Mobil LIDAR tekniği ile üretilmiş sayısal halihazır haritaları, konumsal doğruluk bakımından karşılaştırılmış ve mobil LIDAR tekniğinin doğruluğu irdelenmiştir.

Çalışma bölgesi Türkiye'nin Ordu İli Akkuş İlçesi'dir. Akkuş; Orta Karadeniz'in iç kısımlarında, Canik Dağları üzerinde, Argan Tepesi eteğinde kurulmuş olup engebeli bir topografyaya sahiptir. İlçe yüksek tepelerler çevrilidir ve bu tepeler orman ve bitki örtüsüyle kaplıdır (URL 1, 2019).

GNSS alıcıları ve Total Station cihazları kullanılarak gerçekleştirilen yersel çalışmalarda, 58 adet nirengi noktası kullanılmıştır. Yerleşimin olmadığı alanlardaki detay noktaları GZK GNSS yöntemiyle, yerleşimin olduğu alanlardaki detay noktaları ise Total Station cihazları kullanılarak takeometrik yöntemle ölçülmüştür. Detay noktalarının koordinatları, $3^{\circ}$ UTM (Universal Transvers Merkator) projeksiyonunda ve ITRF96 (International Terrestrial Referance Frame 1996) datumundadır. Detay noktalarının ortometrik yükseklikleri, yerel geoid dayanak noktaları ağından enterpole edilerek elde edilmiştir. Yersel yöntemle üretilen sayısal halihazır harita Şekil 2 'de verilmiştir. 


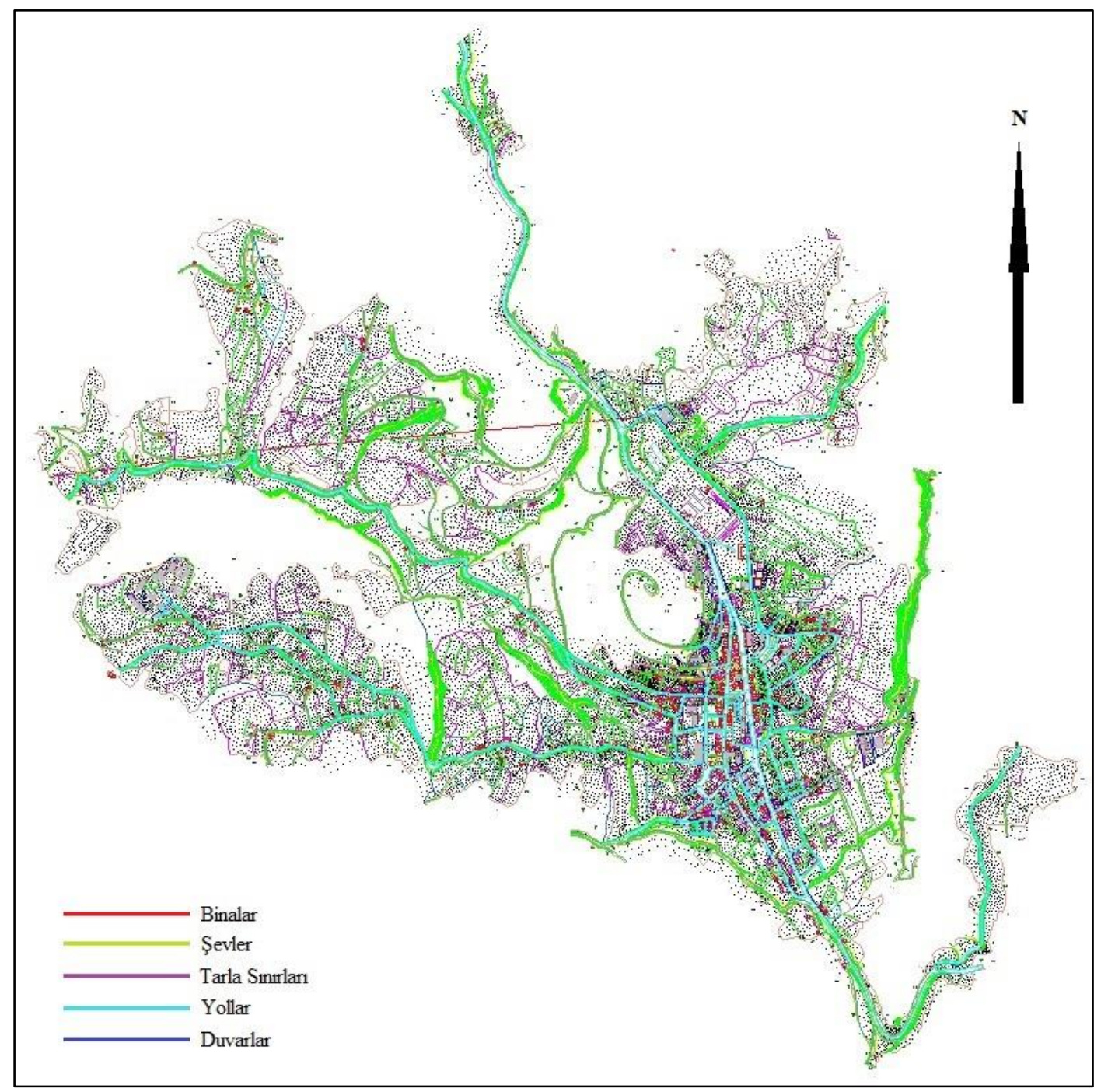

Şekil 2. Yersel yöntemle üretilen sayısal halihazır harita

Bu haritada, siyah noktalar yerleşimin olmadığı alanlardaki detay alımı noktalarını, kırmızı çizgiler binaları, yeşil çizgiler şevleri, mor çizgiler tarla sınırlarını, açık mavi çizgiler yolları ve koyu mavi çizgiler de duvar vb. objeleri temsil etmektedir.

Mobil LIDAR ölçümleri ve bu ölçümlerin değerlendirilmesi Koyuncu LIDAR Harita ve Mühendislik Firmas1 tarafindan gerçekleştirilmiştir. Değerlendirme sonucunda yatay koordinatlar ve elipsoidal yükseklikler belirlenmiş, daha sonra bu elipsoidal yükseklikler ortometrik yüksekliklere dönüştürülmüştür. Mobil LIDAR tekniğiyle üretilen haritada 12 adet nirengi noktası kullanılmıştır. Koordinatlar, yersel yöntemle üretilen haritada olduğu gibi $3^{\circ}$ UTM projeksiyonunda ve ITRF96 datumundadır. Şekil 3'de Mobil LIDAR tekniği ile üretilen harita görülmektedir.

Bu haritada, siyah noktalar yerleşimin olmadığı alanlardaki detay alımı noktalarını, kırmızı çizgiler binaları, yeşil çizgiler şevleri, mor çizgiler tarla sınırlarını, kahverengi çizgiler yolları ve açık mavi çizgiler de duvar vb. objeleri göstermektedir.

Yersel yöntemler ile üretilen sayısal halihazır harita ile Mobil LIDAR tekniği ile üretilen sayısal halihazır harita, bir bilgisayar destekli çizim programında üst üste çakıştırılarak karşılaştırılmıştır. Karşılaştırma için, yersel yöntemlerle üretilen sayısal halihazır haritadaki tüm noktasal ve çizgisel detaylar bordo renge dönüştürülüp altllk olarak kullanılmış, Mobil LIDAR tekniği ile üretilen sayısal halihazır haritadaki tüm noktasal ve çizgisel detaylar da mavi renge dönüştürülerek altlık olarak kullanılan harita üzerine açılmıştır (Şekil 4). 


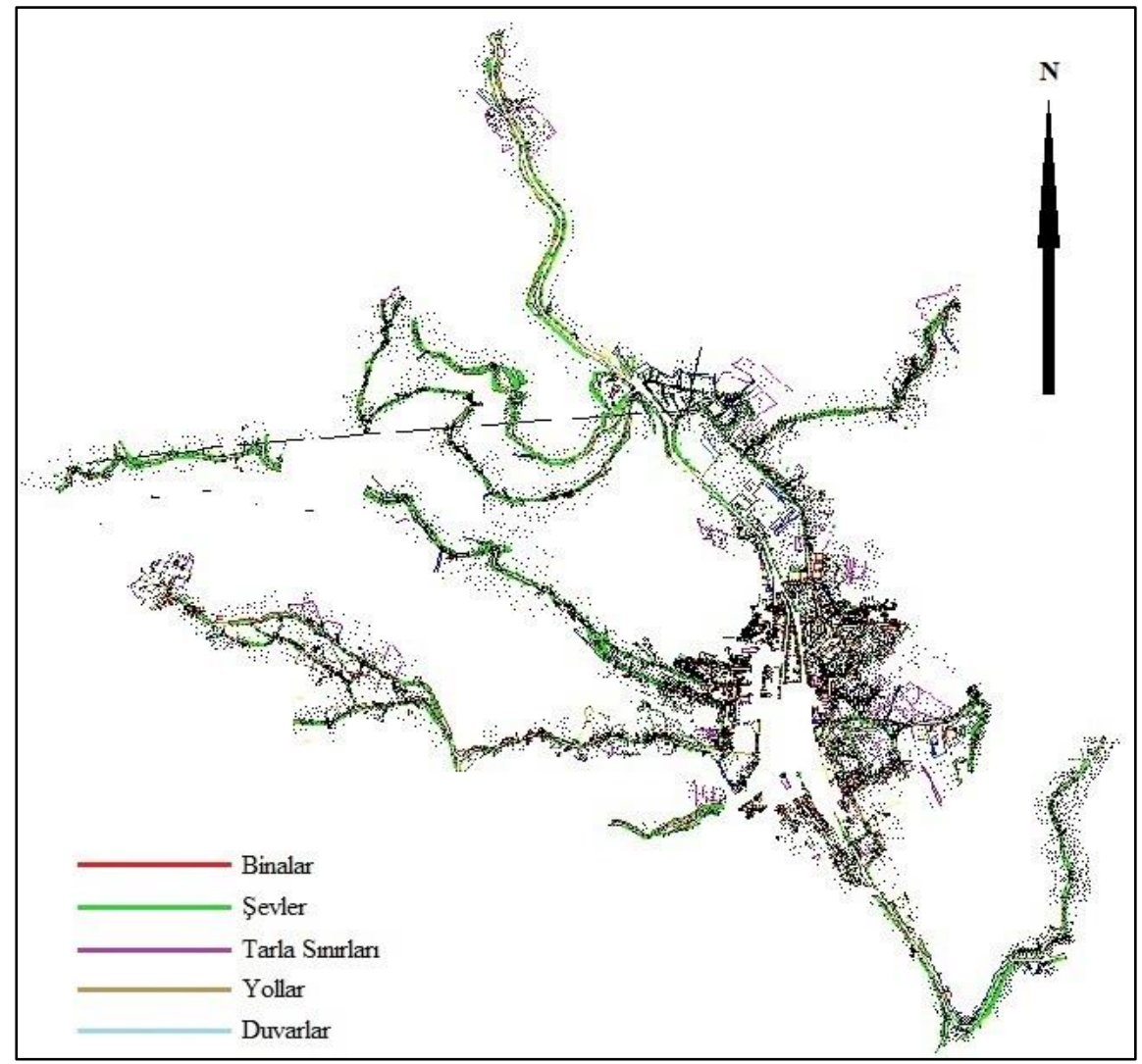

Şekil 3. Mobil LIDAR tekniği ile üretilen sayısal halihazır harita

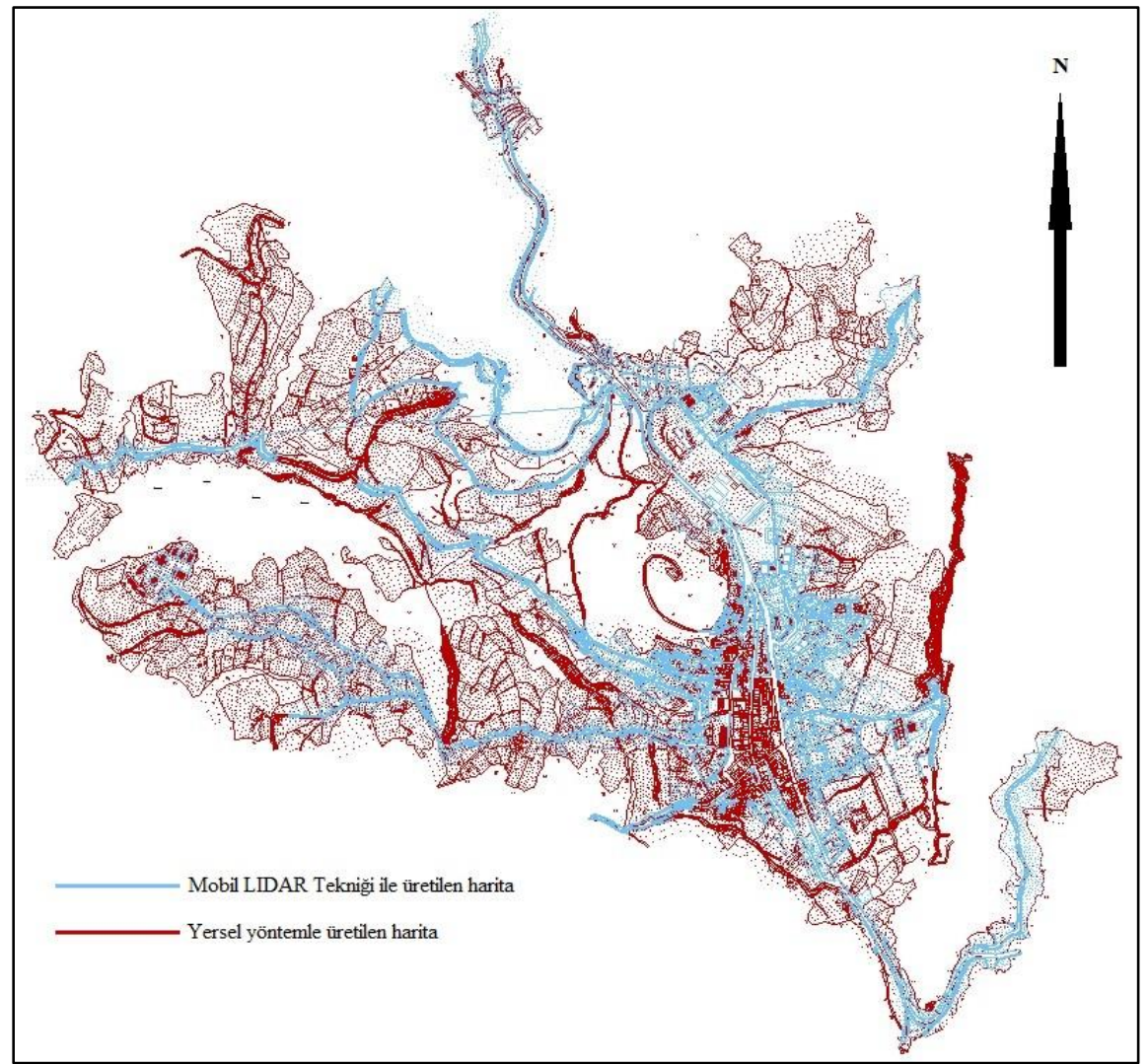

Şekil 4. Karşılaştırma için çakıştırılmış sayısal hâlihazır haritalar 
Şekil 4 incelendiğinde, Mobil LIDAR tekniğiyle üretilen haritada bazı detayların, özellikle yerleşimin olmadığı alanlardaki detay noktalarının eksik olduğu göze çarpmaktadır. Ayrıca yerleşimin olduğu alanların bir kısmında da eksiklerin olduğu görülmektedir. Görüntü yakınlaştırılıp çizgi kalınlıkları arttırıldığında eksiklikler ve farklar daha net belli olmakta, bazı binaların ancak yarım olarak çizilebildiği fark edilmektedir (Şekil 5).

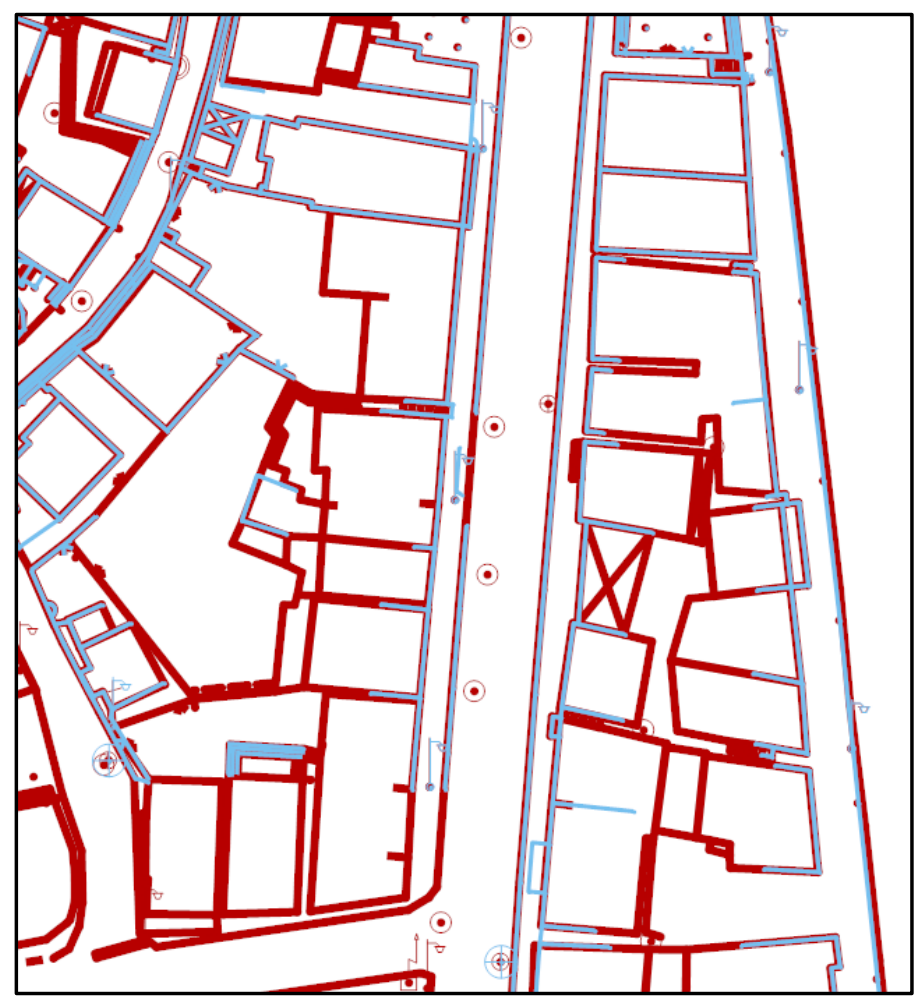

Şekil 5. Yakınlaştırılmış çakışı karşılaştırma görüntüsü

İki farklı yöntemle elde edilen haritalardaki aynı detay noktalarının konum farklılıkları irdelenmiş ve bu farklılıklar Şekil 6'da görüldüğü üzere, bir elektrik direği ve bir bina köşesi ile örneklendirilmiştir. Söz konusu detay noktalarının konumları arasındaki fark $11 \mathrm{~cm}$ olarak belirlenmiştir.

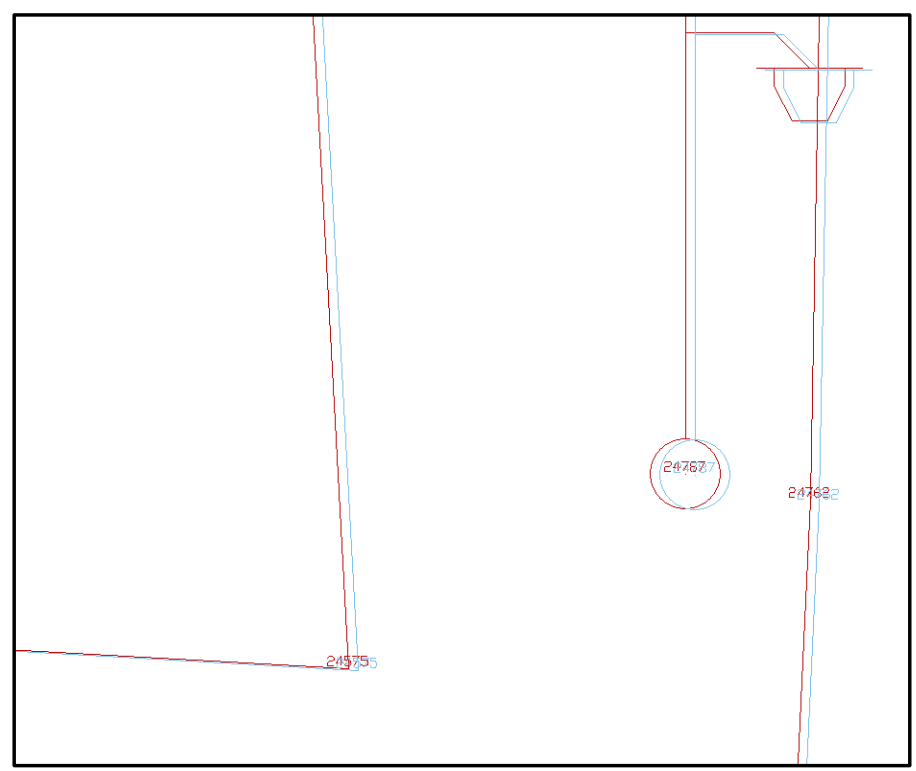

Şekil 6. Aynı detay noktalarının farklı yöntemlerle elde edilen haritalardaki konum farklılıkları

Haritası üretilen bölgede yaklaşık olarak 30.000 adet detay noktası her iki yöntemle de ölçülmüş ve yatay koordinatları ile ortometrik yükseklikleri hesaplanmıştır. Bu 30.000 adet detay noktasının her iki yöntemden elde 
edilen konumlarının farklarının ortalaması; Y yönünde $10 \mathrm{~cm}, \mathrm{X}$ yönünde $2 \mathrm{~cm}$ ve yükseklikte $3 \mathrm{~cm}$ olarak elde edilmiştir. Bu farklar, BÖHHBÜY'de belirtilen sınır değerler olan 10 cm'yi aşmamaktadır (BÖHHBÜY, 2005).

\section{5) SONUÇ VE ÖNERILLER}

Bu çalışmada; Türkiye'nin Ordu İli Akkuş İlçesi’nde, Koyuncu LIDAR Harita ve Mühendislik Firması tarafından Mobil LIDAR tekniği ile üretilen sayısal halihazır harita, yersel yöntemlerle üretilen sayısal halihazır harita ile karşılaştırılarak konumsal doğruluk analizi yapılmıştır. İki yöntemin karşılaştırılması, sonuç ürün olan harita çizimleri üzerinden yapılmıştır. Çizimler üst üste çakıştırılıp birbiri arasındaki farklar belirlenmiştir.

Yerleşimin olmadığı alanlarda Mobil LIDAR'ın detay noktalarını ölçmede yetersiz kaldığı görülmüştür. Bunun sebebi, LIDAR sisteminin araca monteli bir sistem olmasından dolayı yol olmayan veya aracın giremediği bölgelerde ölçüm yapamamasıdır. Yerleşimin sık olduğu bazı bölgelerde de eksik ölçümler gözlemlenmiştir. Bu da, birbirine çok yakın binaların arasında ölçüm yapılırken, araçtaki GNSS alıcısının uydu sinyallerini alamamasından kaynaklanmaktadır. Bunun yanı sıra, Mobil LIDAR bazı bölgelerde binaların arkalarını göremediği için o bölgeler ölçülememiş ve bu nedenle bu binaların tamamı haritalanamamıştır. Bu gibi olumsuzlukları ortadan kaldırmak için, Mobil LIDAR tekniğinin yersel yöntemlerle desteklenmesi şarttır.

Yersel yöntemlerle üretilen harita referans olarak kabul edildiğinde, Mobil LIDAR tekniği ile üretilen haritadaki detay noktalarının konumlarındaki farklılıklar BÖHHBÜY'e göre kabul edilebilir sınırlar içerisinde kalmaktadır. $\mathrm{Bu}$ da, Mobil LIDAR'la ölçülen detay noktası konumlarının doğruluğunun kabul edilebilir düzeyde olduğu anlamina gelmektedir.

Sonuç olarak; haritası üretilecek olan alanın Mobil LIDAR tekniğine çok uygun olması gerekliliği (her detay noktasına araçla ulaşımın imkânının olması, binaların çok yüksek ve birbirlerine çok yakın olmaması, ağaçların sık olmaması gibi), sistemin maliyetinin çok yüksek olması ve çok büyük boyutlarda olan verileri depolama problemleri, Mobil LIDAR tekniğinin dezavantajları olarak sıralanabilir. Sistemin en önemli avantajları ise, alanı çok hızlı bir şekilde tarayarak alım yapabilmesi ve milyonlarca noktadan oluşan nokta bulutu üretebilmesidir. Bu nokta bulutu sayesinde özellikle SYM ve SAM üretiminde oldukça başarılı sonuçlar alınabilmektedir.

\section{Kaynaklar}

Arslanoğlu, M. (2002). Gerçek zamanl kinematik GPS'in kent bilgi sistemi uygulamalarında kullanılabilirliğinin araştırılması. Yüksek Lisans Tezi, Zonguldak Bülent Ecevit Üniversitesi Fen Bilimleri Enstitüsü, Zonguldak.

BÖHHBÜY, (2005). Büyük Ölçekli Harita ve Harita Bilgileri Üretim Yönetmeliği. 15.07.2005 ve 25876 Say1lı Resmi Gazete.

Eren, K. \& Uzel, T. (1995). GPS ölçmeleri. Yıldız Teknik Üniversitesi, Yayın No 301, İstanbul.

HGM (Harita Genel Müdürlüğü), (2019), Haritanın Tanımı, Özellikleri, Sınıflandırmalar. [Online] Available: https://www.harita.gov.tr/images/egitim/87245f4b1d0d12c.pdf (Şubat, 2019)

Hofmann, W.B., Lichtenegger, H. \& Collins, J. (1997). GPS theory and practice. (4th ed.). Springer -Verlag, Newyork.

Kahveci, M. \& Yıldız, F. (2001). GPS global konum belirleme sistemi. (1. Basım). Nobel Yayın Dağıtım, Ankara.

Koç, S., Taşdemir, İ. \& Dinç, O. (2015). Mobil haritalama yöntemi ile panorama istanbul projesi. TUFUAB VIII. Teknik Sempozyumu, 21-23 Mayıs 2015. Konya.

KLHM (Koyuncu Lidar Harita ve Mühendislik), (2019), Available: http://www.lidarharita.com/\# (Şubat, 2019)

Sickle, V.J. (1996). GPS for land surveyors.(1st Ed). Ann Arbor Pres Inc.,Michigan. 
Tepeköylü, S. (2016). Mobil lidar uygulamaları, veri işleme yazıllmları ve modelleri. Geomatik Dergisi, 1(1).

Teunissen, P.J.G. \& Kleusberg, A. (1998). GPS for geodesy. (2nd ed.). Springer, Verlag, Berlin.

URL 1. (2019), Available: https://www.akkusilcesi.com/cografyasi/ (Şubat, 2019)

Yalçın, Ö. (2014). Insansız kara araçlarında 2d lidar kullanarak yol sinırları tespiti. Yüksek Lisans Tezi, Kocaeli Üniversitesi Fen Bilimleri Enstitüsü, Kocaeli. 